\title{
Chapter 3 - Beyond Conspicuous Compassion: Indigenous Australians Deserve More Than Good Intentions
}

\section{Senator Amanda Vanstone, Minister for Immigration and Multicultural and Indigenous Affairs}

\section{Lecture presented 7 December 2005}

I acknowledge the traditional owners of the land on which we're meeting today. I acknowledge the richness of the culture that prospered here in the past and also the strength of the culture that continues to enrich Australians in the $21^{\text {st }}$ century. However I must also acknowledge the frustration of looking at the last 30 years of Indigenous policy in this country and not seeing results anywhere near good enough to show for it. Life for too many of our first Australians continues to be unhealthy, unhappy, violent and short.

\section{A time for change}

Surely we can all agree on one thing. For First Australians, this can not be as good as it gets, it cannot be the best we can do. We can, and we must, do better.

For the Australian government, states and territories, the public service around Australia, the private sector, the community generally and First Australians themselves, things have to change. The goodwill at different levels of government and across party lines is such as I have never seen before.

We have an extraordinary opportunity for change. To grasp that opportunity we must be prepared to tell it like it is and we cannot accept lower standards for First Australians than we do for other Australians. This rare opportunity has to be seized. We have to be sure footed. We need to face reality. Indeed, a reality check is nearly always more effective and much, much fairer than half-baked promises.

As they do with other Australians, all governments have to accept their proper responsibilities for First Australians. Government departments have to deliver. The private sector needs opportunities to play a part. Equally, Indigenous people have to accept responsibility and play their part.

\section{More than good intentions}

Good intentions are all very well but will not be good enough on their own. We need to be prepared to make the tough decisions. We must back Indigenous 
Australians in their aspirations and in building their future. The time for thinking that we know what's best for Indigenous Australians has passed.

The environment will be challenging for those who are comfortable indulging in what has been called 'conspicuous compassion' - a culture of ostentatious caring which is about feeling good, not doing good. Caring but not making change condemns Aboriginal people to some sort of cultural museum where they should expect less than others. Some people find conspicuous compassion quite therapeutic - for themselves. These are the people who still feel uncomfortable with mutual obligation and fret about what is needed to tackle welfare dependency - who would rather see another generation of Aboriginal Australians marginalised than confront the debilitating effects of passive acceptance of handouts.

If we are going to change things we have to be able to call a spade a spade. I see more willingness from people like Sue Gordon, Warren Mundine and Noel Pearson to confront these realities than from possibly well-meaning but out-of-touch commentators. In my experience Aboriginal people have no problem with the notion of mutual obligation or shared responsibilities. These principles draw very much from longstanding aspects of Aboriginal culture - in central Australia, for example, the Ngaanyatjatjara (nundarra) people have long used the words Ngapartji Ngapartji to describe what we would call mutual obligation.

In the name of self-determination, it seems that Aboriginal and Torres Strait Islander Commission (ATSIC) did little more than set up Indigenous people for failure. The hands-off approach of governments - at all levels - helped institutionalise mismanagement, corruption and exploitation. It allowed self interest and the unscrupulous to undermine attempts to make things better.

\section{Standards}

It is time to start treating Indigenous Australians like every other citizen. They can no longer be denied the opportunities that other Australians expect. They need to be given every opportunity to share in the rich experience of Australian life.

We must overcome the sense that ordinary Australian aspirations are out of reach for Indigenous Australians. Things like: healthy, happy kids; a good day's pay for a good day's work; and, aspirations for a better life. Expectations can and must be lifted. The idea of Indigenous people as passive recipients of whatever governments provide has to be rejected once and for all.

For too long we have accepted a different standard for Indigenous people. The understandable abhorrence of the injustices of the past has led in some ways to a reluctance to be critical and to respond firmly when we should have. A fear of doing more harm led us to doing very little. Why have we tolerated more neglect for children in remote Aboriginal communities? Why do we tolerate 
inadequate school attendance? Why do we accept less in terms of educational standards? By doing so we condemn Indigenous kids to a life with less opportunity than as Australians, as First Australians, they are entitled to.

\section{Responsibilities}

There is no way to avoid it - different standards have short-changed Indigenous people. We must not accept poorer levels of service or poorer outcomes for Indigenous people. This is why the Australian Government decided last year, to end the practice of separate policy development and program delivery for Indigenous people.

The programs previously administered separately by ATSIC are now being administered by mainstream departments which now clearly carry the responsibility for providing services to all Australians. They cannot pass the buck on these issues.

At the same time we are requiring them to work together to solve problems that cross many areas of responsibility. No one should underestimate the difficulty of pulling together this kind of whole-of-government approach. The 'stovepipes' of government policy and programs have grown up over many decades and cannot be undone overnight. This reform task is the other side of shared responsibility - governments taking responsibility for their bit. Shared responsibility means Indigenous Australians taking responsibility in their own communities; but it also means governments delivering on their responsibilities.

That said, I am proud of how far we have come over the last 12 months. We have successfully negotiated 121 Shared Responsibility Agreements with 98 communities. Some of these agreements may seem modest to outsiders, but as the expression of the aspirations of these communities and the desire to improve the lives of their children, we are starting to see some hopeful signs.

Our Indigenous Coordination Centres (ICC) which are located all around the country - from Kalgoorlie to Nhulunbuy, Roma to Ceduna, Tamworth to Melbourne - are meant to lead this process from the ground up. These ICCs are made up of teams of people from different departments. We have put the people together and the task now is to get them working together and to respond directly to the needs of local people. In some places such as NSW they are also co-located with state government staff.

In Canberra there is an unprecedented commitment to driving real change in the way governments do business. The relevant Ministers meet together regularly as do the Secretaries. None of this is easy, bureaucracies have a history of failing Aboriginal people. But we are going to keep pushing ahead, we are determined that the service the Australian government provides will be less complex, more flexible and make a real difference. 
It is pleasing to see that some states and territories are making important moves in the same direction. While I appreciate the growing level of cooperation from the states and territories, nonetheless we will occasionally have disagreements. Some will not agree with my view that all the states and territories should be much more transparent in accounting for what they do with and for Indigenous Australians. For example, it might interest you to know that $\$ 1.1$ billion of Goods and Services Tax (GST) revenues flowing to states is diverted to those jurisdictions with higher proportions of remote Aboriginal populations such as Queensland, Western Australia and the Northern Territory. There is little transparency in what happens to this money and how much of it finds its way to Indigenous people.

I am keen to ensure that all money allocated to improve outcomes for indigenous people is actually reaching them where they live - and not bloating bureaucracies, both government and non-government, or being used for other things. I am also sure the states such as NSW and Victoria with lower proportions of Indigenous people and which therefore subsidise the other states and the northern territory are as interested as I am in ensuring that it is being used for the purposes intended. If this money is being invested wisely we should be able to look forward to the day when the relative disadvantage has diminished and redistribution on this scale will not be needed.

Governments do not always have the solutions. It is very heartening to see the private sector's growing role in Indigenous affairs. Forward-thinking mining companies have long seen the value of a constructive engagement with Indigenous people. It is inspiring to see major banks, retailers and others in the corporate sector really engaging with Indigenous Australia and getting results that governments would not achieve. I could tell you about some of them but I am a bit worried about promoting one bank or retailer over another. There are potentially many more creative ideas within the private sector that could respond to some of the issues facing Indigenous people.

\section{Land}

Aboriginal land provides an excellent example of different standards being simply accepted without question. In the Northern Territory 45 per cent of land is Aboriginal land. However as I have said before, being land rich but dirt poor is not good enough. There is no romance in communal poverty. It crushes individual motivation and condemns all too passive acceptance of more of the same. Something has to change and it will.

The government's commitment to protect the right of communal ownership of Aboriginal land is rock solid. It will be preserved for future generations. Within that framework we have started a new and productive debate about how Aboriginal people can draw economic benefits from their land. Recent 
announcements in conjunction with the Northern Territory are the first steps in helping Aboriginal people to own their own homes and to develop businesses in townships, just as we non-Indigenous people have always been able to do.

The current arrangements actually leave many Aboriginal people without control over their lives. This is because traditional owners are but a subset of people who live on Aboriginal lands. The historical displacement of Aboriginal people has left many Aboriginal residents of communities on Aboriginal land which is not their own country and therefore they have no traditional power and no real security of tenure. They live effectively in a feudal system at the pleasure of the traditional owners, which unfortunately sometimes involves arbitrary decisions that pass out largesse to favoured family and friends.

While acknowledging the justice of the land rights decisions, I think there is an underlying injustice here that needs remedying. Our proposals to streamline leasehold arrangements, where traditional owners agree, and to provide incentives to purchase homes will go some way to improve this situation. When implemented, they will provide incentive for the development of businesses to service Aboriginal towns and the people in them. Importantly, they will also give people the chance to effectively own their own home.

The National Indigenous Council in this area has done some tremendous work. The general reception to our recent announcements on land rights and native title has been refreshingly constructive. I am all for a robust debate on the merits of different approaches. But at last it seems that maybe we are slowly moving away from some of the old entrenched ideological positions in Indigenous affairs and towards a more business-like appraisal of the benefits for Indigenous people. This can only be for the better.

\section{Townships and homelands}

Giving people a chance to own their own home is an important step towards having the same standards. We also need to look at treating Indigenous communities as what they are - small towns.

If we called the larger Aboriginal communities towns instead of communities, it might help put the difference in perspective. You might be confronted with questions like:

- Why doesn't the Council look after things like water, rubbish and sewerage in this town?

- Why do kids in this town not go to school?

- Why do the authorities not seem to care?

- Why can you not buy your own house in this town?

- Why do people not pay rent for their houses? 
These are ordinary questions about ordinary things that do not happen in these places because they are dealt with differently. We want that to end.

Why should essential services in these towns be provided by annual grants from the Commonwealth and not through the same sort of arrangements that work in hundreds of other little towns around Australia?

People in communities should not have to be burdened with responsibilities for town infrastructure which most of us in this room would struggle to manage. Community councils should be able to concentrate on tackling local issues and building capacity and hope in the future. Then they should not be worrying about next year's power contract. Indigenous community structures are fragile enough without being ground down by being landed with responsibilities for delivering services that are rightfully the responsibility of governments.

Some jurisdictions are moving in the right direction. In the Northern Territory, for example, we are working quite closely with the Territory government to establish Regional Authorities that essentially extend local government arrangements to remote Indigenous people. In other words, normalisation and delivery of government services.

This normalisation relates to the major townships. However we need to think about the large numbers of very small settlements or homelands. There are around 1,000 communities with less than 100 people, and of those, more than 80 per cent have less than 50 people. Despite the higher rate of population growth of Aboriginal people, it is unlikely that many of these homelands will grow to become viable towns. We have started talking to the Northern Territory and other governments about these issues.

They raise some important issues for the future such as:

- How viable are they?

- While some are doing OK and helping with drug rehabilitation and maintenance of culture, others may be risky environments, particularly for women and children

- What level of amenity can be expected to be provided to small settlements in some cases hundreds of kilometres from each other?

All Australians living in remote areas of the country have less access to services and support than those in more populated areas. There is an acceptance of a level of self-dependence. Perhaps we need to explicitly draw a line on the level of service that can be provided to homeland settlements.

We need a wider debate about this. Listening to Indigenous Australians does not mean blindly accepting, for example, that services - such as education, health and housing - can be delivered at equal levels and equally well in 
townships and the homelands for the same people. We have to be realistic and we have to be honest.

\section{Education}

Education is another area where for too long different standards have been delivered and different standards have been accepted. And guess what we have ended up with - different standards again for First Australians. In many of our remote schools different standards are expected of Indigenous children. We use excuses like cultural difference to explain to ourselves why they cannot learn. Does this mean we are saying they are somehow less intelligent? If you expect less and then you give less, you get less.

Second-rate education offering the preservation of Indigenous culture as its objective does not provide a basic education that Indigenous Australians should be able to expect.

Everywhere in the world, hope for the future starts with education. Parents not sending their children to school is a powerful statement of their loss of faith in a better future. The longer it takes us to tackle this, the more children are missing opportunities to truly determine their own future.

States and territories must take action to get kids to school and retain their interest. They must recruit bright and effective teachers who will relish the challenges and rewards of making a difference, like in Cherbourg. States should start publishing attendance rates in communities. Unless we face reality, we cannot hope to build a better future. Some of our innovative approaches such as the 'no school, no pool' initiative are starting to pay off. We need more new ideas.

\section{Conclusion}

For kids, education is everything. But we cannot hope to give that to them if their communities are not safe, their housing is inadequate and their health is lousy. As I said before we have never had opportunities for change like those that are before us today. We do not want to look back in 10 years time and say that we wished we had taken the chance when the opportunity was there for the taking.

We will waste that opportunity if we are not prepared to tell it like it is. We have got to be courageous and deliver results. Good intentions are not good enough. Indigenous Australians must be able to expect the same range of opportunities as other Australians. No more cultural museums that might make some people feel good and leave Indigenous Australians without a viable future. Continuing cultural identity does not require poverty or isolation from mainstream Australian society. 
We are talking fundamental change, changing the way governments relate to Indigenous Australians. Making sure they deliver to their Indigenous citizens as they do to all other citizens.

As long as 100 years ago, Theodore Roosevelt, in a very elegant political speech entitled 'A Strenuous Life' highlighted the point that worthy goals are not easily achieved. The changes we need to make will certainly not be easy but, as Roosevelt pointed out, a strenuous life is a life worth living. 